\title{
Contrast sensitivity function of sine-wave gratings in children with acute malnutrition
}

\author{
Natanael Antonio dos Santos, Caroline Costa Gomes Alencar and Yuri Henrique Nunes Dias \\ Universidade Federal da Paraíba, Brazil
}

\begin{abstract}
The aim of this study was to determine the contrast sensitivity curves of sine-wave gratings with spatial frequencies of 0.25 , 1.0, 2.0 and 8.0 cycles per degree (cpd) of visual angle in 16 female subjects aged 7 to 9 years old, eight well-nourished and eight with acute protein-energy malnutrition (PEM). All participants had normal visual acuity and were free of identifiable ocular illness. Contrast threshold was measured using a temporal two-alternative forced-choice psychophysical method, at a distance of $150 \mathrm{~cm}$ of the stimuli, binocularly, with mean luminance of $40.1 \mathrm{~cd} / \mathrm{m} 2$. We detected a general decline in contrast sensitivity for children with acute malnutrition at all spatial frequencies compared to well-nourished children. The malnourished group needed in average 1.37 times more contrast to detect the stimulus in comparison with the well-nourished one. Differences between the groups were statistically significant at all spatial frequencies $(\mathrm{p}<.001)$. These results suggest that acute PEM changes the visual perception for sine-wave gratings.Keywords: visual perception, contrast sensitivity, spatial frequency, malnourished children, psychophysical method.
\end{abstract}

Received 14 September 2008; received in revised form 1 June 2009; accepted 17 June 2009. Available online 29 June 2009

\section{Introduction}

For decades, studies reported that protein-energy malnutrition (PEM) during development promotes structural and functional changes in the brain (Galler, Shumsky, \& Morgane, 1996; Levitsky \& Strup, 1995; Scrimshaw, 1998) as well as behavioral changes. (Galler et al., 1996; Scrimshaw, 1998; Strupp \& Levitsky, 1995; Tonkiss, Galler, Morgane, Bronzino, \& Austin-Lafrance, 1993). Besides, literature reports show that PEM causes neurophysiological changes in the visual system (VS) of rats, for example: (1) retinal and lens damages (Bonavolonta, Ferrante, \& Rosati, 1989; Bonavolonte, Ferrante, Terracciano, \& Vecchione, 1991), (2) deficit in number and size-frequency distribution of the optic nerve fiber (Bedi \& Warren, 1983), (3) decrease in the synapsesto-neuron ratio (Bedi \& Warren, 1983; Bedi, Massey, \& Smart, 1989; Gundappa \& Desiraju, 1988) and structure changes in the pyramidal cells of the visual cortex (Díaz-

Natanael Antonio dos Santos, Caroline Costa Gomes Alencar, and Yuri Henrique Nunes Dias, Laboratório de Percepção, Neurociências e Comportamento (LPNeC), Departamento de Psicologia da Universidade Federal da Paraíba, Brazil. Correspondence regarding this article should be directed to: Natanael Antonio dos Santos. Departamento de Psicologia, CCHLA-UFPB, Cidade Universitária, João Pessoa, PB, Brazil, CEP 58059-900. Phone: (55 83) 3235-4439. Fax: (55 83) 3216-7064. E-mail: natanael_labv@yahoo.com.br / natanael.santos@pq.cnpq.br
Cintra, Cintra, Ortega, Kemper, \& Morgane, 1990). However, only a few studies investigated the effects of PEM in the human sensory development (Dantas, Brandt \& Leal, 2005; Durmaz, Karagol, Deda, \& Külküf Önal, 1999; McDonald, Joffe, Barnet, \& Flinn, 2007; Thordstein et al., 2004). Among them, McDonald and colleagues (2007) conducted an electrophysiological study with flash visual-evoked potentials in infants and found reductions in at least one of the positive and negative components peaks. Also, Dantas and colleagues (2005), in a clinical study with preschool children, found (i) reduction in visual acuity (Teller's cards), (ii) higher incidence of myopia and astigmatism, (iii) and posterior eye changes - such as less stained optic nerve. However, no studies have been found that used contrast threshold or the contrast sensitivity function (CSF) to assess the consequences of PEM in visual functions and in children's visual perception.

Contrast is the difference in visual properties that makes an object (or its representation in an image) distinguishable from other objects and the background. This study used the contrast sensitivity function, CSF, defined as the inverse of contrast threshold (Cornsweet, 1970) to evaluate the basic sensory functions of children with and without history of acute malnutrition (acute PEM). The measurement of the contrast sensitivity or threshold is established experimentally by the minimum amount of contrast (dependent variable) that the visual system needs to detect a stimulus or spatial frequency (independent variable). For example, the contrast for each 
spatial frequency can be adjusted with a psychophysical procedure until the visual system can discriminate a pattern with a spatial frequency from another with a homogeneous field with mean luminance. According to Bar (2004), different spatial frequencies convey different information about the appearance of a stimulus. High spatial frequencies represent abrupt spatial changes in the image (such as edges), and generally correspond to fine details of the configuration. Low spatial frequencies, on the other hand, represent global information about the shape (such as general orientation and proportions).

Then, the CSF is a practical and behavioral way to assess how diseases or other conditions interact with the nervous system and how this is reflected in practical visual responses. It may be also useful to characterize the visual system response of acutely or currently malnourished children, as the normal CSF values have an established standard range.

The CSF is a classic technique that has been used to investigate and diagnose functional changes in visual pathways in the central nervous system (Akutsu \& Legge, 1995; Bour \& Apkarian, 1996; Elliott \& Situ, 1998; Polat, Sagi, \& Norcia, 1997; Slaghuis \& Thompson, 2003; Suttle \& Turner, 2004 Ventura et al., 2005; Vleugels, van Nunen, Lafosse, Ketelaer, \& Vandenbussche, 1998). The fundamental idea about using the CSF is that the sensitivity reduction or sensory threshold rising, according to a given spatial frequency, is often a sign of changes in the mechanisms or in the sensory pathways that process contrast.

\section{Method}

\section{Participants}

Sixteen female subjects aged 7-9 years old, eight without malnutrition and with normal weight $(\mathrm{M}=8.4$, $\mathrm{SD}=0.9)$ and eight with acute PEM $(\mathrm{M}=8.5$; $\mathrm{SD}=$ $0.8)$ participated in this experiment. The children had normal visual acuity (6/6) and no history of ocular or neurological diseases. Visual acuity was assessed with a Rasquin chart of "E" optotypes.

The acutely or currently malnourished children were selected and ranked according to Waterlow's classification of anthropometric parameters which are based on rates of height/age $(\mathrm{H} / \mathrm{A})$ and weight/height $(\mathrm{W} / \mathrm{H})$ and are recommended for children from 2 to 10 years old (Sigulem, Devincenzi, \& Lessa, 2000). Acute or currently malnourished children showed $\mathrm{H} / \mathrm{A}$ rates above $90 \%$ and $\mathrm{W} / \mathrm{H}$ below $90 \%$ the benchmark 50 percentile, whereas the children without malnutrition had appropriate height and weight based on the benchmark index for age according to sex (for a review on the diagnosis of the nutritional status of children and adolescents, please see Sigulem et al., 2000).

The participation of both children groups in the research occurred only with their parents' (or legal guardian) signature of a free and informed consent, according to Resolution No. 196/96 of the Health National Council (Health Ministry, Brazil), which issues the guidelines and standards for research involving human beings. The project was approved by the Ethics Committee of the Health Sciences Centre of the UFPB.

\section{Equipment and Visual Stimuli}

The stimuli were generated and displayed in the centre of a CRT-based LG digital chromatic 19-inch video monitor with high resolution (1024 x 768), 70-Hz frame rate, and input controlled by a microcomputer through a video board with VGA and DVI connectors. The voltage luminance of the monitor was expanded 8 bits to 14 bits with BITS++ (Cambridge Research Systems, Rochester, Kent, England, 2002), allowing the use of high-resolution visual stimuli. The software LightScan, equipped with OptiCAL Photometry (Cambridge Research Systems, Rochester, Kent, England, 2002) measured the screen luminance and performed the monitor's gamma correction, using as sample 48 index values ranging from 0 to 255 (gamma $=1.8$ ). The lowest and highest luminance values of the screen were $0.20 \mathrm{~cd} / \mathrm{m}^{2}$ and 80.0 $\mathrm{cd} / \mathrm{m}^{2}$ (mean luminance of $40.1 \mathrm{~cd} / \mathrm{m}^{2}$ ) and the luminance of the stimulus surrounding was the same as that of the lowest luminance. The size of the room was $2.5 \times 2.0$ $\mathrm{m}$ illuminated by a Philips, fluorescent $20 \mathrm{~W}$ bulb; the walls were gray for better control of the room lightning conditions during the experiment. A computer program developed by the Laboratório de Percepção, Neurociências e Comportamento (LPNeC), developed in $\mathrm{C}++$, was used to run the experiment (generate the stimuli, control the stimuli presentation and record contrast thresholds).

The achromatic and vertical static sine-wave grating stimuli with spatial frequencies of $0.25,1.0$, 2.0 and 8.0 cycles per degree (cpd) of visual angle used to measure the CSF were defined as:

$$
L(x)=\operatorname{Lm}[1+\operatorname{csin}(2 \pi f x+\varphi)]
$$

where $\mathrm{L}(\mathrm{x})$ is the luminance value at one point on the sine wave, Lm is the mean luminance, $\mathrm{c}$ is the contrast (Michelson's formula), $f$ is the frequency in terms of cycles per degree, and $\varphi$ is the spatial phase.

All the stimuli had a diameter of approximately 7.2 degrees of visual angle and were designed to be presented in the middle of the monitor screen at a distance of $150 \mathrm{~cm}$ from the observer (Figure 1). A fixed chair and a table with chin and forehead supports were used to avoid changes in this distance.

\section{Procedure}

An experimental design with repeated measurements was used, in accordance with general practices in the research on visual perception using psychophysical methods. Studies of this nature involve a small number of volunteers in each condition or 


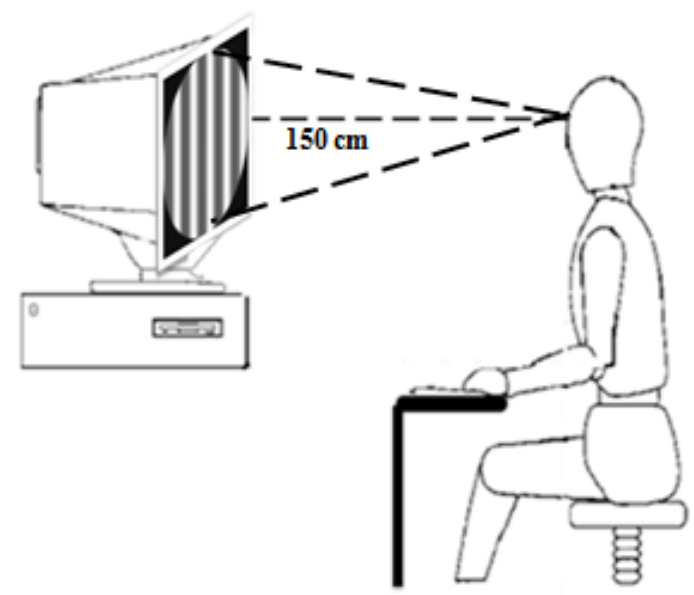

Figure 1. Stimulus presentation scheme. The stimuli were originally calibrated to be seen at a distance of $150 \mathrm{~cm}$ in a $19^{\prime \prime}$ display.

group (Adams \& Courage2002; Benedek, Benedek, Kéri, \& Janáky, 2003; Campbell \& Robson, 1968), because each group goes through all conditions at different times and orders. The order effect was controlled by the counterbalancing technique. The experimental design was composed of one dependent variable (contrast threshold) and one independent variable (malnutrition) as the between subject factor.

The contrast threshold measurements were achieved using a temporal two-alternative forcedchoice psychophysical method (Santos, Oliveira, Nogueira, \& Simas, 2006; Santos, Simas, \& Nogueira, 2007; Wetherill \& Levitt, 1965). This method is based on the probability of consecutive correct choices made by participants after the presentation of pairs of stimuli, in this case, in each pair of stimuli, one had only mean luminance $(40.1 \mathrm{~cd} / \mathrm{m} 2$, neutral stimulus) and another contained one of the spatial frequencies (test stimulus). Luminance contrast was measured using Michelson's formula:

$$
C=\frac{\operatorname{Lmax}-\operatorname{Lmin}}{\operatorname{Lmax}+\operatorname{Lmin}}
$$

where $\mathrm{C}$ is the contrast, $\mathrm{Lmax}$ is the highest luminance, and Lmin is the lowest luminance. (Michelson, 1891).

A correct choice was to select the spatial frequency stimulus (first or second of each pair). The order of stimuli presentation in each pair was random and controlled by the program. The test stimuli were presented in suprathreshold level with an initial contrast of .079. The criterion to reduce contrast by one unit $(20 \%)$ was three consecutive correct answers and one incorrect answer to increase by the same unit. This yielded a probability of perceiving the sine-wave stimuli set at $79 \%$.

An experimental session started with a brief beep followed by the presentation of a stimulus (test or neutral) during 2 s with an inter-stimulus interval lasting $1 \mathrm{~s}$ and presentation of the other stimulus during $2 \mathrm{~s}$, followed by the volunteer's response. The interval between stimuli pairs and trials was $3 \mathrm{~s}$. A different beep gave feedback to the volunteer in each correct choice. The duration of each experimental session depended on the responses given by the participant and ended only after three pairs of peaks and valleys were obtained (six contrast threshold values). It generally lasted about 5-10 minutes.

Each contrast threshold was measured two times, always on different days, for each participant, totalizing 12 values measured for each participant to each frequency. The thresholds were measured at a distance of $150 \mathrm{~cm}$, with binocular vision and natural pupil.

All participants received the following statement: "a sequence of circles one with clear-dark stripes and another totally gray, will be presented. You must always choose the circle that contains the stripes, pressing the button on the left (button number 1) of the mouse when the circle with stripes is presented first, and the button on the right (button number 2) when it is presented in the second place (after the gray drawing)". It is important to mention that each session began with the test stimulus with contrast in supra-threshold level and that the experiments only started when the investigator was convinced that the participants understood and responded as instructed.

\section{Results}

After each session, the program produced a result sheet with the experimental situation and the contrast thresholds achieved by the reversals. The mean of the 12 contrast threshold values obtained for each participant to each frequency were grouped into spreadsheets by condition (with and without malnutrition), and the mean values were

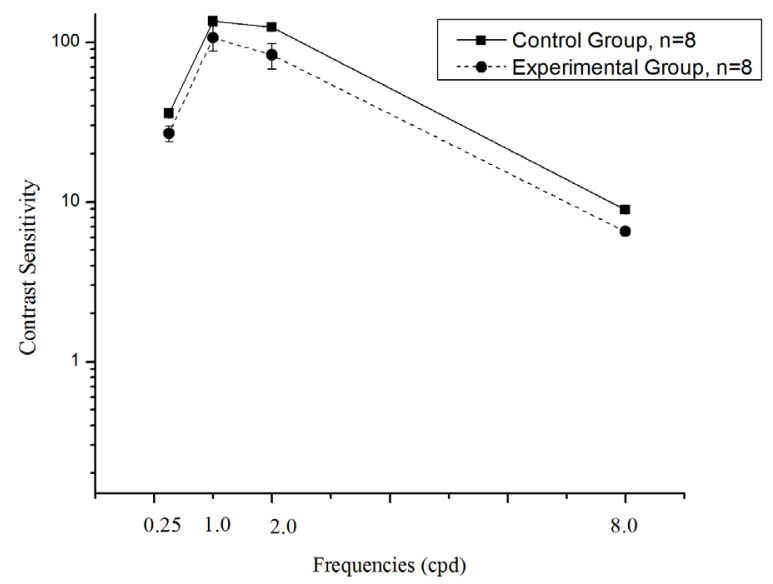

Figure 2. The estimated contrast sensitivity of 7 to 9 year old children is shown as a spatial frequency function of $0.25,1.0,2.0$ and $8.0 \mathrm{cpd}$. The mean error bars were corrected to the sample's size to represent a $95 \%$ confidence interval. The continuous curve (- - - ) represents the children without acute PEM, and the dotted curve (---•---), the children with acute PEM. 
Table 1. Mean values of contrast thresholds found for $0.25,1.0$, 2.0 and $8.0 \mathrm{cpd}$ in each condition (CG and $\mathrm{EG})$ and the ratio between $C G$ and $E G$ mean values.

\begin{tabular}{lrccc}
\hline SC/Frequency & $\mathbf{0 . 2 5}$ & $\mathbf{1 . 0}$ & $\mathbf{2 . 0}$ & $\mathbf{8 . 0}$ \\
\hline Control Group & 35.89 & 135.81 & 124.73 & 8.91 \\
Experimental Group & 26.83 & 106.76 & 83.07 & 6.53 \\
Ratio & 1.34 & 1.27 & 1.50 & 1.36 \\
\hline
\end{tabular}

used as an estimate of contrast sensitivity to each tested spatial frequency. Figure 2 shows the contrast sensitivity curves (CSF) for children with and without acute PEM.

The results showed that the maximum sensitivity occurred in the frequency range of $1.0 \mathrm{cpd}$ to children with and without acute PEM (Figure 2). The data also showed that children without malnutrition were 1.34 , $1.27,1.50$ and 1.36 times more sensitive to detect the spatial frequencies of $0.25,1.0,2.0$ and $8.0 \mathrm{cpd}$, respectively, than malnourished children (Table 1). Thus, the results indicate that the CSF of malnourished children was lower than that of children without malnutrition, i.e., the children without malnutrition needed less contrast to detect the spatial frequencies tested than the group with acute PEM.

The one-way ANOVA showed a significant difference between groups, $F(1,11)=32.5$, $(\mathrm{p}<.001)$; and intercept, F $(1,11)=204.4$, $(\mathrm{p}$ $<.001)$. The post-hoc Tukey HSD test applied to the contrast sensitivity data showed that the differences between the groups were statistically significant for all spatial frequencies; $0.25 \mathrm{cpd}(\mathrm{p}$ $<.05) ; 1.0 \mathrm{cpd}(\mathrm{p}<.001) ; 2.0 \mathrm{cpd}(\mathrm{p}<.001)$; and $8,0 \mathrm{cpd}(\mathrm{p}<.001)$. The results show that the sensitivity to spatial frequencies is higher in children without malnutrition as compared to malnourished children.

\section{Discussion}

The main purpose of this research was to characterize the CSF of children aged 7 to 9 years old, with and without acute PEM, using a temporal two-alternative forced-choice psychophysical method. The data showed that this function is different for children with and without acute PEM. Malnutrition caused a decrease in sensitivity at all spatial frequencies, i.e., the children without malnutrition were on average 1.37 times more sensitive to detect the spatial frequencies of $0.25,1.0$, 2.0 and $8.0 \mathrm{cpd}$ than the children with malnutrition. It is possible to see that the greatest change between the two groups occurred in the range of $2.0 \mathrm{cpd}$, where the wellnourished group was approximately 1.5 times more sensitive than the malnourished children.

These results suggest that the global behavior of the CSF is different to both groups (Figure 2), which implies that the performance of malnourished children to distinguish an object from other objects and the background at low contrast levels is reduced; and that acute PEM may interact with the mechanisms that process low, medium and high spatial frequencies. This interaction reduces the children's ability to process global information regarding the stimulus shape (conveyed by low spatial frequencies) and fine details (conveyed by high spatial frequencies), considering that each frequency range conveys different information about an object (Bar, 2004).

Contrast sensitivity reduction related to PEM was already expected because the literature shows functional and structural damages in the malnourished brain (Galler et al. 1996; Levitsky \& Strup, 1995; Scrimshaw, 1998) and PEM also affects the visual system in animals (Bedi et al., 1983,1989; Bonavolonta et al., 1989; 1991; Diaz-Cintra et al., 1990; Gundappa \& Desiraju, 1988). Furthermore, the results of this study corroborate recent evidence showing electrophysiological changes in the vision of infants and children in preschool age with PEM (Dantas et al., 2005; McDonald et al., 2007; Thordstein et al., 2004). However, it is impossible to make a direct comparison between the results of this study with the above quoted investigations, since there are sample, theoretical and methodological differences among the studies that make any comparison impossible. For example, the anthropometric parameters used to classify and diagnose malnutrition vary according to age (Sawaya, 2006; Sigulem, Devincenzi, \& Lessa, 2000). Even the Waterlow classification is only suitable for children aged between 2 and 10 years (Sigulem et al., 2000). Furthermore, it is difficult to attribute the changes found in the CSF only to acute PEM, as malnutrition is generally associated with various nutritional deficiencies, such as essential fatty acids, micro-nutrients, among others (Guesry, 1998). However, this is one of the problems encountered when attempting to study the effects of malnutrition in humans and that is the reason why studies that have a high internal validity are conducted on animals. The anthropometric parameters alone, although important, are not sufficient for an accurate diagnosis of the children's nutritional status without the help of clinical and/or biochemical trials.

\section{Final considerations}

In general terms, the results of this study revealed changes in the CSF of children from 7 to 9 years old with acute PEM classified according to Waterlow anthropometric parameters. These sensory changes found in the perception or in the visual contrast processing related to recent PEM are important and indicate the need for further research with humans to systematically assess the effects of malnutrition in the visual development of children. It is also important to measure the CSF of children with malnutrition using photopic and scotopic levels of luminance to investigate if there is any relation between malnutrition and changes in 
magnocellular and parvocellular visual pathways, because in this study only one range of photopic luminance $(40.1 \mathrm{~cd} /$ $\mathrm{m}^{2}$ ) was used. Further empirical research should clarify the effects of malnutrition in children, as well as give a basis to policies aimed at nutritional monitoring, mainly during development. It is within this perspective that the LPNeC intends to direct malnutrition and visual perception studies.

\section{Acknowledgements}

\section{State Health Secretariat / João Pessoa- Paraíba.}

\section{References}

Adams, R.J., \& Courage, M.L. (2002). Using a single test to measure human contrast sensitivity from early childhood to maturity. Vision Research, 42, 1205-1210.

Akutsu, H.S., \& Legge, G.E. (1995). Discrimination of compound gratings: Spatial-frequency channels or local features? Vision Research, 35, 2685-2695.

Bar, M. (2004). Visual objects in context. Nature Reviews Neuroscience, 5, 617-29.

Bedi, K.S., Massey, R.F., \& Smart, J.L. (1989). Neuronal and synaptic measurements in the visual cortex of adult rats after undernutrition during normal or artificial rearing. The Journal of Comparative Neurology, 289, 89-98.

Bedi, K.S., \& Warren, M.A. (1983). The effects of undernutrition during early life on the rat optic nerve fiber number and size-frequency distribution. The Journal of Comparative Neurology, 219, 125-132.

Benedek, G., Benedek, K., Kéri, S., \& Janáky, M. (2003). The scotopic low-frequency spatial contrast sensitivity develops in children between the ages of 5 and 14 years. Neuroscience Letters, 345, $161-164$

Bonavolonte, O., Ferrante, P., \& Rosati, G. (1989). Retinal and lens damages observed in young rats undergoing protein malnutrition at selected stages of their growth. International Journal for Vitamin and Nutrition Research, 59, 117-121.

Bonavolonte, O., Ferrante, P., Terracciano, L., \& Vecchione, R. (1991). Further researches about retinal damages and dietary protein imbalance in growing rats. International Journal for Vitamin and Nutrition Research, 61, 251-257.

Bour, L.J., \& Apkarian, P. (1996). Selective broad-band spatial frequency loss in contrast sensitivity functions. Comparison with a model based on optical transfer functions. Investigative Ophthalmology \& Visual Science, 37, 2475-2484.

Campbell, F.W., \& Robson, F.G. (1968). Application of the Fourier analysis to the visibility of gratings. Journal of Physiology, 197, 551-566.

Cornsweet, T.N. (1970). Vision Perception. New York: Academic Press.

Dantas, A.P., Brandt, C.T. \& Leal, D.N.B. (2005). Manifestações oculares em pacientes que tiveram desnutrição nos primeiros seis meses de vida. Arquivo Brasileiro de Oftalmologia, 68, 753-756.

Diaz-Cintra, S., Cintra, L., Ortega, A., Kemper, T., \& Morgane, P.L. (1990). Effects of protein deprivation on pyramidal cells of the visual cortex in rats of three age groups. The Journal of Comparative Neurology, 292, 117-126.

Durmaz, S., Karagol, U., Deda, G., \& Külküf Önal, M.Z. (1999). Brainstem auditory and visual evoked potentials in children with protein-energy malnutrition. Pediatrics International, 41, 615-619.

Elliott, D.B., \& Situ, P. (1998). Visual acuity versus letter contrast sensitivity in early cataract. Vision Research, 38, 2047-2052.
Galler, J.R., Shumsky, J.S., \& Morgane, P.J. (1996). Malnutrition and brain development. In: Walker, W.A., \& Watkins, J. (orgs.). Nutrition in Pediatrics (2) (pp. 194-210). Neuilly sur-Seine, France: Plenm Press.

Guesry, P. (1998). The role of nutrition in brain development. Preventive Medicine, 27, 189-194.

Gundappa, G., \& Desiraju, T. (1988). Deviations in brain development of F2 generation on caloric undernutrition and scope of their prevention by rehabilitation: Alterations in dendritic spine production and pruning of pyramidal neurons of lower laminate of motor cortex and visual cortex. Brain Research, 456, 205-223.

Levitsky, D.A., \& Strup, B.J. (1995). Malnutrition and brain: Changing concepts, changing concerns. Journal of Nutrition, $125,2212 \mathrm{~S}-2220 \mathrm{~S}$.

Mcdonald, C.G., Joffe, C.L., Barnet, A.B., \& Flinn, J.M. (2007). Abnormal ash visual evoked potentials in malnourished infants: An evaluation using principal component analysis. Clinical Neurophysiology, 118, $896-900$

Michelson, A.A. (1891). On the application of interference methods to spectroscopic measurements. I. The London, Edinburgh, and Dublin Philosophical Magazine and Journal of Science, Fifth Series, 31, 338-346 and Plate VII.

Polat, U., Sagi, D., \& Norcia, A.M. (1997). Abnormal long-range spatial interactions in amblyopia. Vision Research, 37, 737-744.

Santos, N.A., Oliveira, A.B., Nogueira, R.M.T.B.L., \& Simas, M.L.B (2006). Mesopic radial frequency contrast sensitivity function for young and older adults. Brazilian Journal of Medical and Biological Research, 39, 791-794.

Santos, N.A., Simas, M.L.B., \& Nogueira, R.M.T.B.L. (2007) Contrast Perception in Human Beings: Psychophysical Evidence for High Angular Frequency Channels. Psicologia: Reflexão \& Crítica, 20(1), 559-567.

Sawaya, A.L. (2003). Desnutrição: Consequências a Longo Prazo e Efeitos da Recuperação Nutricional. Estudos Avançados, 17(48), 147-158.

Scrimshaw, N.S. (1998). Malnutrition, Brain, Learning, and Behavior. Nutrition Research, 18, 351-379.

Sigulem, D.M., Devincenzi, M.U., \& Lessa, A.C. (2000). Diagnóstico do Estado Nutricional da Criança e do Adolescente. Jornal de Pediatria, 76, 275-284.

Slaghuis, W.L., \& Thompson, A.K. (2003). The effect of peripheral visual motion on focal contrast sensitivity in positive- and negativesymptom schizophrenia. Neuropsychologia, 41, 968-980.

Strupp, B.J., \& Levitsky, D.A. (1995). Enduring cognitive effects of early malnutrition: a theoretical reappraisal. Journal of Nutrition, $125,2221 \mathrm{~S}-2232 \mathrm{~S}$.

Suttle, C.M., \& Turner, A.M. (2004). Transient pattern visual evoked potentials in children with Down's syndrome. Ophthalmic and Physiological Optics, 24, 91-99.

Thordstein, C.M., Sultan, B.L., Wennergren, M.M., Tornqvist, E.T., Lindecrantz, K.G., \& Kjellmer, I. (2004). Visual Evoked Potentials in Disproportionately Growth-Retarded Human Neonates. Pediatric Neurology, 30, 262-270.

Tonkiss, J., Galler, J., Morgane, P.J., Bronzino, J.D., \& Austin-Lafrance, J. (1993). Prenatal protein malnutrition and postnatal brain function. Annals of the New York Academy of Sciences, 678, 215-227.

Ventura, D.F., Simões, A.L., Tomaz, S., Costa, M.F., Lago, M., Costa, M.T.V. Canto-Pereira, L.H.M., de Souza, J.M., Faria, M.A.M., \& Silveira, L.C.L. (2005). Colour vision and contrast sensitivity losses of mercury intoxicated industry in Brazil. Environmental Toxicology and Pharmacology, 19, 523-529.

Vleugels, L., van Nunen, A., Lafosse, C., Ketelaer, P., \& Vandenbussche, E. (1998). Temporal and spatial resolution in foveal vision of multiple sclerosis patients. Vision Research, 38, 2987-2997.

Wetherill, G.B., \& Levitt, H. (1965). Sequential estimation of points on a psychometric function. The British Journal of Mathematical and Statistical Psychology, 48, 1-10. 